\title{
Bimodal magnetic-fluorescent nanostructures for biomedical applications $\dagger$
}

\author{
Joseph J. Gallagher, ${ }^{* a}$ Renata Tekoriute, ${ }^{b}$ Julie-Ann O'Reilly, ${ }^{a}$ Christian Kerskens, ${ }^{a}$ Yurii K. Gun'ko ${ }^{* b}$ \\ and Marina Lynch $^{a}$
}

Received 25th March 2009, Accepted 8th May 2009

First published as an Advance Article on the web 19th May 2009

DOI: $10.1039 / b 906023 p$

\begin{abstract}
Magnetite-based polyelectrolyte-coated nanostructures were fabricated and the potential for biomedical application assessed in mixed glial cell cultures with nanostructure cellular internalization, cytotoxicty and contribution to magnetic resonance contrast generation all examined.
\end{abstract}

Several experimental techniques in bioscience research have utilized magnetic nanoparticles; these include cell sorting, ${ }^{1}$ cell labelling, ${ }^{2}$ targeted drug delivery, ${ }^{3}$ magnetic resonance imaging (MRI), ${ }^{4}$ and magnetic thermotherapy. ${ }^{5}$

The use of these particles in animal experiments to track labeled cells using MRI has led to the visualisation of cell migration in various pathologies. Macrophage and T-cell infiltration from the bloodstream to brain tissue, specifically the cerebellum, in animals with experimental autoimmune encephalitis (EAE), which is an animal model of multiple sclerosis, has been visualised using this technique. ${ }^{6}$ Macrophage migration to the site of a cerebral blood vessel infarct in animal stroke models has been similarly examined. ${ }^{7}$ The serial and non-invasive nature of MRI allows the repeated interrogation of a living specimen but the lack of resolution at a cellular level is a limitation of this technique. In contrast, fluorescence microscopy affords greater spatial resolution and greater potential to examine the behaviour of fluorescent contrast agents at the cellular level. ${ }^{8}$ Therefore the use of MRI and fluorescence microscopy are complementary in biomedical research. The use of a bi-modal magnetic-fluorescent nanostructure ${ }^{9}$ would enable the capabilities of both these techniques to be exploited.

Iron-oxide based magnetic nanoparticles have become the most widely used superparamagnetic contrast agent in MRI. Their effect on the relaxation time of water is measurable even at nanomolar concentrations. As a result, the nanoparticulate agents are in many ways complementary to the gadolinium agents. Nanoparticulate agents also have advantages with respect to biocompatibility, selective uptake, targeted delivery and removal from the body, which can be relatively easily modified by changing the size and the nature of the surface coating of nanoparticles. These factors are particularly important for in vivo medical applications. ${ }^{10}$ The main aims of our work are to develop and investigate new multimodal magnetic-fluorescent nanostructures by combining a magnetic and a fluorescent

\footnotetext{
${ }^{a}$ Trinity College Institute of Neuroscience, Trinity College, Dublin, Ireland. E-mail: jjgallag@tcd.ie; Fax: +00353896 8513; Tel: +00353 8968412 ${ }^{b}$ Department of Chemistry, Trinity College, Dublin, Ireland

$\uparrow$ Electronic supplementary information (ESI) available: Experimental procedures, $\zeta$-potential, optical spectroscopy, SQUID, nuclear magnetic resonance, dispersion measurements of nanostructures and TGA. See DOI: 10.1039/b906023p
}

entity in one species and utilise these nanomaterials for biological imaging applications.

There are several reports on the application of multimodal magnetic-fluorescent nanomaterials for cellular imaging. For example, biocompatible iron oxide nanoparticles conjugated to a fluorescent dye and the Tat-peptide have been investigated, using confocal microscopy and T2-weighted MRI, following incubation with primary human dermal fibroblast cells and Madin-Darby bovine kidney derived cells. ${ }^{11}$ In another study, rhodamine-labeled citric acid-capped magnetite nanostructures were utilised as fluorescent biological markers. These nanostructures were shown to be readily taken up by $\mathrm{KB}$ cells in vitro and exhibited a response to applied magnetic fields. ${ }^{12}$ Bertorelle et al. ${ }^{13}$ have demonstrated intracellular uptake of maghemite nanoparticles, functionalized with rhodamine B and fluorescein, in HeLa cells. It was found that within HeLa cells, nanostructures were confined inside endosomes. It has also been demonstrated that several cancer cell lines can be labeled by different fluorescent superparamagnetic core-shell nanostructures containing magnetite nanoparticles and fluorescein-5-isothiocyanate (FITC) species. ${ }^{14-16}$

Previous findings have also shown that macrophage and osteoblast cells internalize magnetic-fluorescent nanostructures, which were based on magnetite nanoparticles, octaaminopropylsilsesquioxane and porphyrin. ${ }^{17}$ Additionally it has been demonstrated that one dimensional linear assemblies of magnetic nanoparticles can be utilized as contrast agents in MRI studies in vivo. ${ }^{18,19}$ In our current work we have developed new magnetic-fluorescent nanostructures, based on polyelectrolyte-stabilised magnetic nanoparticle assemblies and rhodamine $\mathrm{B}$, and examined the in vitro performance of these nanostructures in primary mixed glial cell cultures. These new fluorescent-magnetic nanostructures consist of linear chain like-assemblies of magnetic nanoparticles, where rhodamine $\mathrm{B}$ molecules are linked to polyelectrolyte coating by weak ionic bonding and can be differentiated from the magnetic-fluorescent nanostructures discussed above.

Initial magnetite nanoparticles were produced by reacting a mixture of ferrous and ferric chlorides (2:1 molar ratio) and polysodium-4-styrene sulfonate (PSSS) aqueous solution with ammonia. ${ }^{12}$ A layer-by-layer assembly approach, similar to previously reported magnetite-quantum dot composites, was used. ${ }^{20}$ The magnetite-PSSS nanomaterials were coated with alternating positively charged pol$\mathrm{y}$ (allylamine hydrochloride) $(\mathrm{PAH})\left(2.85 \times 10^{-7} \mathrm{M}\right.$ solution $)$ and negatively charged PSSS polyelectrolyte $\left(2.85 \times 10^{-7} \mathrm{M}\right.$ solution $)$ multilayers (10 layers in total). This was necessary to coat and isolate the magnetic nanoparticle cores from direct contact with rhodamine B molecules and prevent paramagnetic quenching of the dye.

A positively charged rhodamine B layer was deposited on the last negatively charged PSSS layer. These assembly processes were 


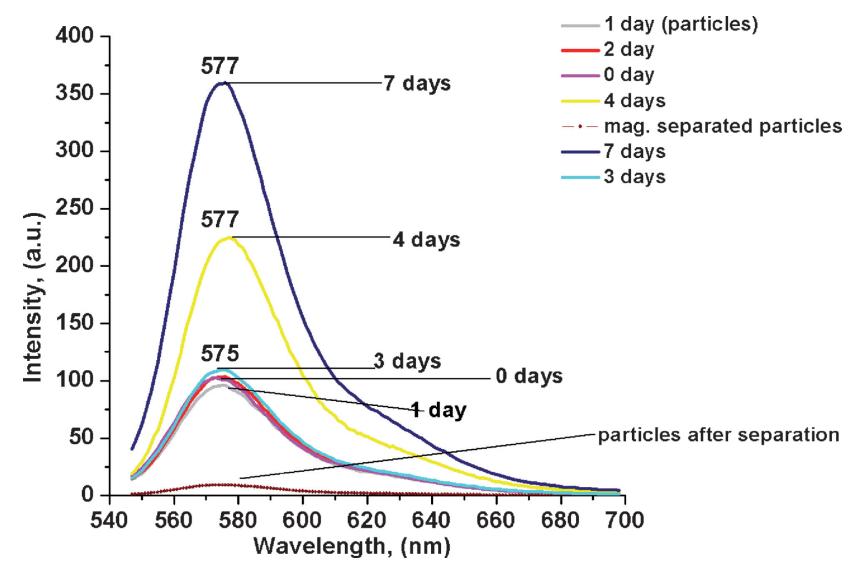

Fig. 1 An aqueous solution containing the prepared nanostructures was incubated in the dark and at room temperature $\left(20^{\circ} \mathrm{C}\right)$ for 7 days and the emission spectra of $\mathrm{Fe}_{3} \mathrm{O}_{4}$-PSSS-PAH/PE $10-\mathrm{RhB}$ nanomaterials $\left(\lambda_{\mathrm{ex}}=\right.$ $555 \mathrm{~nm}$ ) was monitored using UV-vis. Magnetic separation of any magnetite-nanomaterial ensured only non-bound rhodamine $B$ was assessed. Nanomaterials were shown to be stable until day 4, when some release of rhodamine $\mathrm{B}$ was detected. A further increase in fluorescence was observed at day 7; magnetically-separated and re-dispersed particles from day 7 show no fluorescence suggesting all rhodamine B is detached from the nanostructure at day 7 .

monitored by $\zeta$-potential measurements and optical spectroscopy $\dagger$. The deposition of rhodamine $\mathrm{B}$ resulted in the reduction of the $\zeta$ potential value from $-40 \mathrm{mV}$ to $-25 \mathrm{mV}$. Attempts to coat the rhodamine B layer with an extra PSSS shell resulted in extremely weak fluorescent materials. The data suggest that there is
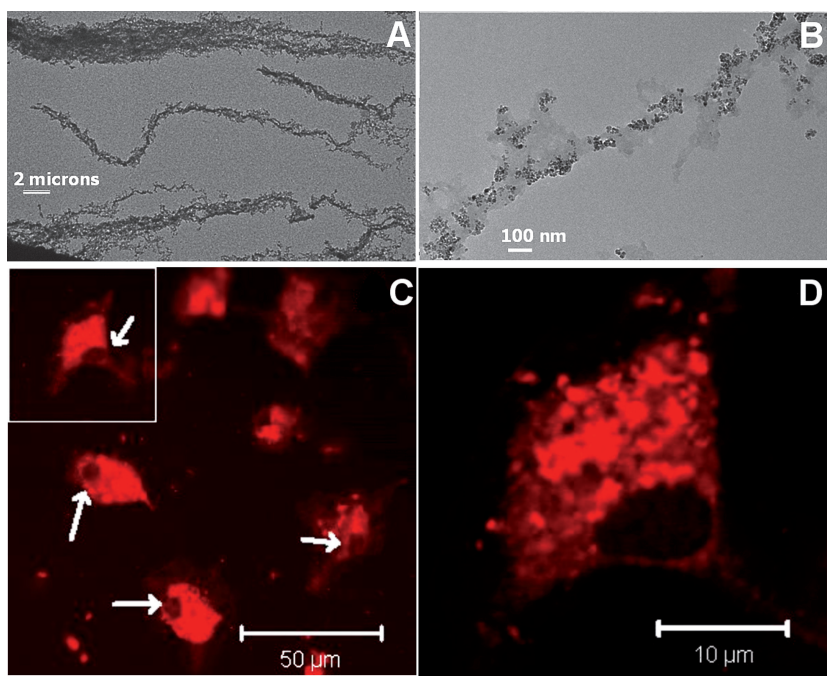

Fig. 2 TEM and confocal microscopy of nanostructures. (A,B) TEM images show nanostructures forming chain-like assemblies following placement in a $0.5 \mathrm{~T}$ magnetic field. (C,D) Confocal micrographs identify internalised nanostructures in primary cortical glial cultures from 1 day old Wistar rats. Cells were incubated in the presence of nanostructures for 2 hours at $37^{\circ} \mathrm{C}$ at a concentration of $2.31 \times 10^{-4} \mathrm{~g} / \mathrm{mL}$ of $\mathrm{Fe}_{3} \mathrm{O}_{4}$. Fluorescence is distributed throughout the cell body and cell nuclei are delineated by the absence of fluorescence. (C) Large field of view demonstrating the internalization of the nanostructures and the delineation of several cell nuclei. Bar $=50 \mu \mathrm{m}$. (D) A smaller field of view image focusing on the boxed area in (C) demonstrates nanostructure distribution in a single cell. Bar $=10 \mu \mathrm{m}$. a preferential interaction between the positively-charged rhodamine $\mathrm{B}$ and free negatively-charged polyelectrolyte, which removes the dye from the nanostructure.

An investigation into the stability of the nanostructure incubated in an aqueous solution, see Fig. 1, shows no release of rhodamine B for the first three days following fabrication. Therefore experiments were restricted to a maximum of incubation period of 2 days and cellular internalization experiments involved a 2 hour incubation period to minimize any potential stability issues.

Tranmission electron microscopy (TEM) images of nanostructures aligned in magnetic field are presented in Fig. 2(A) and (B). The nanostructures appear aggregated showing linear necklace- or chainlike structures following placement in a magnetic field. Analysis by confocal microscopy revealed internalization of nanostructures; Fig. 2(C) and (D) show several examples of cell nuclei, denoted by arrows, delineated by the absence of nanostructures. Prussian blue staining in a sample of these cells confirmed the presence of magnetite $\uparrow$. The spatial distribution of nanostructures, in the cytosol and localised to the cell membrane, is demonstrated in Fig. 3(A) and (B)
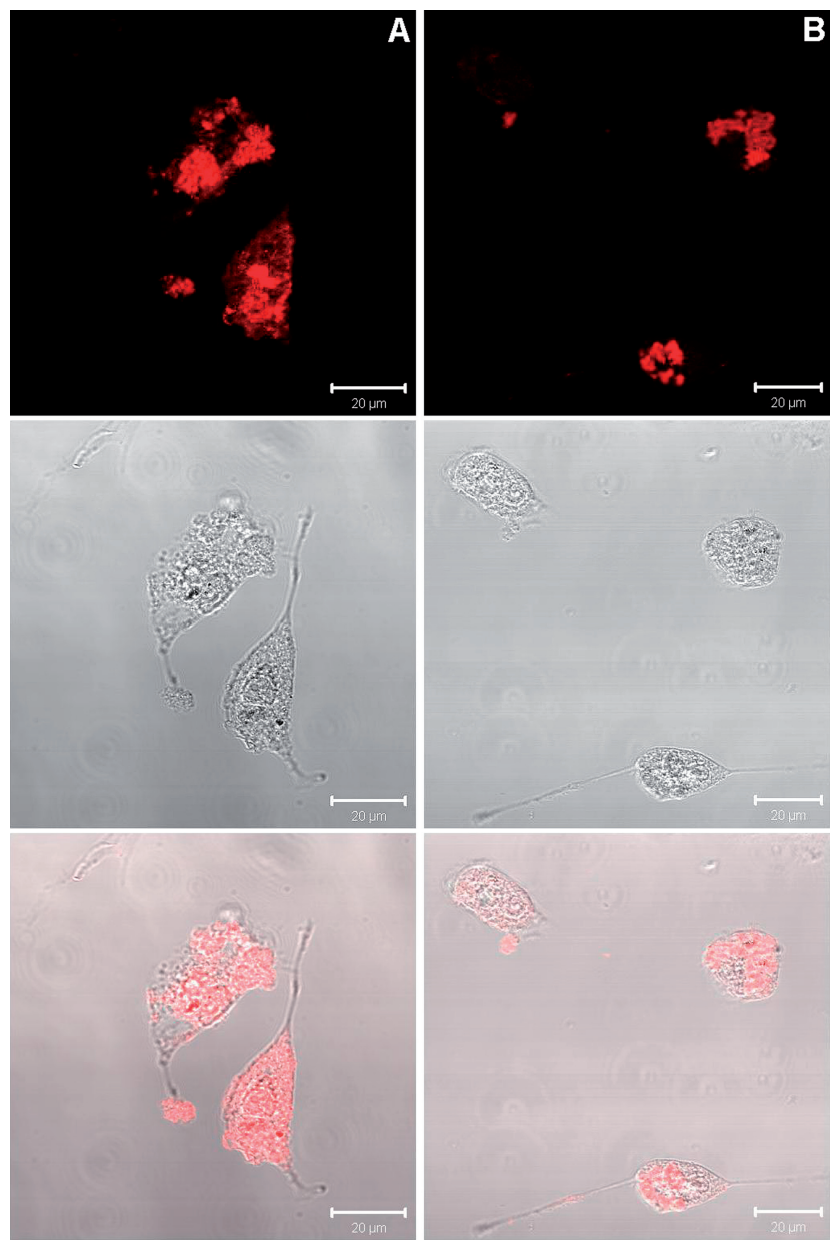

Fig. 3 Fluorescence and phase contrast microscopy reveal nanostructure spatial distribution within cells after a 2 hour incubation period. (A) Fluorescence is visible on the cell membrane. (B) Fluorescence appears more distinctly within the cell and can be seen to delineate the nucleus. Top, fluorescence image; center, phase contrast image of same cells; bottom, overlay of fluorescent and phase contrast images. Bar $=20 \mu \mathrm{m}$. 


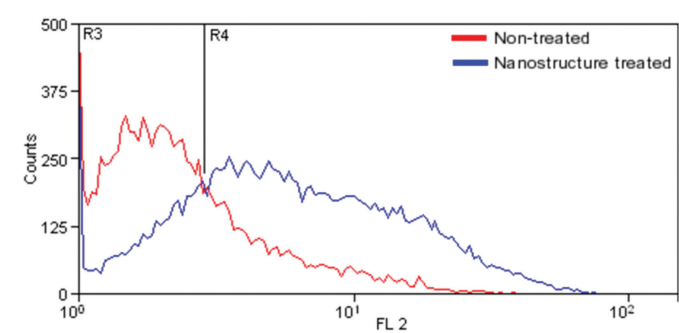

A

B

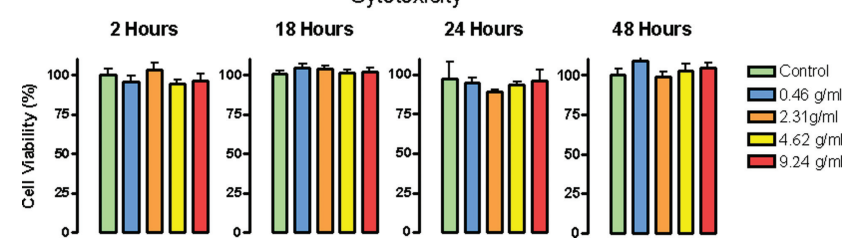

Fig. 4 Flow cytometric and cytotoxicity analysis of nanostructures. (A) Mean peak fluorescence measurements of non-treated and nanomaterialtreated mixed glial cells ( 2 hour incubation at $2.31 \times 10^{-4} \mathrm{~g} / \mathrm{mL}$ of $\mathrm{Fe}_{3} \mathrm{O}_{4}$ ). Gates were set to remove dead cells and non-internalised nanostructures. (B) Analysis of the cytotoxic effects of nanostructures. Incubation of cells in the presence of nanostructures $\left(0.46 \times 10^{-4}, 2.31 \times 10^{-4}\right.$, $4.62 \times 10^{-4}, 9.24 \times 10^{-4} \mathrm{~g} / \mathrm{mL}$ of $\left.\mathrm{Fe}_{3} \mathrm{O}_{4}\right)$ for 2, 18, 24 and 48 hours revealed no evidence of a reduction in cell viability.

respectively. Membrane localization may be a stage in the process of endocytosis, which astrocytes, or perhaps microglia, use to internalize the nanostructure but it could also reflect phagocytic activity of microglial cells. Additional data from experiments conducted on another phagocytic cell, the macrophage, revealed internalized nanostructures (data not shown).

Data from flow cytometric analysis are presented in Fig. 4(A). The mean peak fluorescence increased from 1.34 in control-treated cells (R3), to 7.84 in nanomaterial-treated cells (R4). This correlates with an increase in cells associated with nanostructure fluorescence to $83 \%$. Approximately $30 \%$ of a mixed glial cell population are microglia, capable of phagocytosis of the nanostructure. However, a greater percentage of the nanomaterial-treated cell sample is associated with nanostructure fluorescence suggesting endocytosis of nanostructure by astrocytes, which comprise $70 \%$ of the cells. Cell viability, Fig. 4(B), was not significantly affected by incubation in the presence of nanostructures $\left(0.46 \times 10^{-4}, 2.31 \times 10^{-4}, 4.62 \times 10^{-4}, 9.24 \times 10^{-4}\right.$ $\mathrm{g} / \mathrm{mL}$ of $\mathrm{Fe}_{3} \mathrm{O}_{4}$ ) for 2, 18, 24 or 48 hours.

The field inhomogeneity of MR phantoms versus the number of nanostructure-labeled cells in each phantom is plotted in Fig. 5. The contrast generated by the number of labeled cells in each phantom is linear (Pearson Correlation, $\mathrm{R}^{2}=0.9967, \mathrm{p}<0.001$ ). The offset from the origin is due to the inhomogeniety present in the main static field. Fig. 6(B) demonstrates the linear chain-like assemblies formed by the nanostructures following overnight placement in a $7 \mathrm{~T}$ magnetic field. The arrows illustrate the direction of the magnetic field. This finding is in agreement with TEM images shown in Fig. 2 and correlates well with the previously-reported behaviour of non-fluorescent precursor material (polyelectrolyte stabilised magnetite nanoparticles without multilayered coating and dye). ${ }^{18}$

MRI tracking of labeled cells provides a high level of information not accessible using any other method. However, subsequent analysis of the cells tracked using MRI is difficult to achieve. In EAE, macrophage infiltration into brain tissue due to increased blood brain

\section{$\Delta B$ - Nanocomposite MRcontrast}

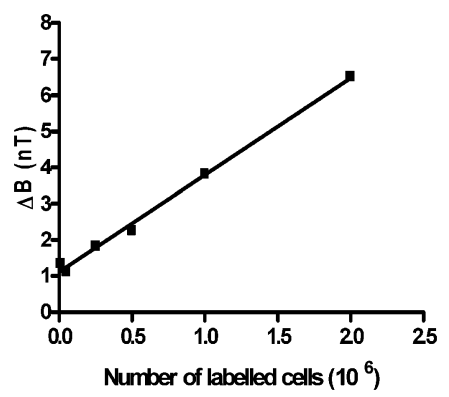

Fig. 5 The contrast $(\Delta \mathrm{B})$ generated by the nanostructures versus number of labeled cells is linear (Pearson Correlation, $\mathrm{R}^{2}=0.9967, \mathrm{p}<0.001$ ). Six cell phantoms were prepared in $2 \mathrm{ml}$ cylindrical Eppendorf tubes, each containing $1 \mathrm{ml}$ of $0.5 \%$ warm agarose gel and $1 \mathrm{ml}$ of nanostructure treated mixed glial cell suspension containing either $2.0 \times 10^{6}, 1.0 \times 10^{6}$, $0.5 \times 10^{6} .0 .25 \times 10^{6}, 0.05 \times 10^{6}$ or $0.01 \times 10^{6}$ cells $/ \mathrm{ml}$. Homogenous distribution of the cells was ensured by 30 seconds of trituration. The field inhomogeneity, $\Delta \mathrm{B}$, due to the presence of the nanostructures was calculated, for each of the phantoms, using $\Delta \mathrm{B} \gamma=(1 / \mathrm{T} 2 *)-(1 / \mathrm{T} 2)$, where $\gamma$ is the gyromagnetic ratio for hydrogen $(42.58 \mathrm{MHz} / \mathrm{T})$.
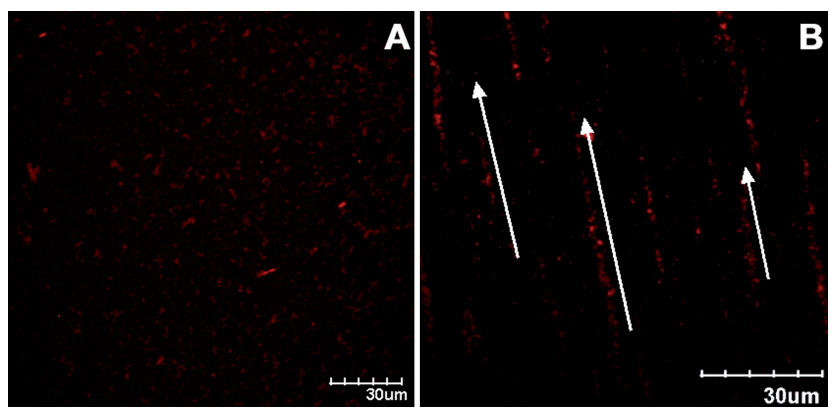

Fig. 6 Confocal microscopy of fluorescent-magnetic nanostructures following overnight placement in the earth's magnetic field (A) and a $7 \mathrm{~T}$ magnetic field (B).

barrier permeability, occurs 7 days after injection of myelin oligodendrocyte glycoprotein to induce the disease. At present, correlation of T2-weighted MR data of contrast agent-labeled macrophages is achieved using light microscopy staining for iron and secondary staining of macrophages or microglia in post-mortem brain tissue. ${ }^{21}$ The use of the nanostructure removes the need to stain for iron and enables confocal microscopy to be utilised for MR correlation and subsequent analysis, for example the expression of cell surface markers. Furthermore, subsequent recovery and investigation of nanostructure labeled cells using fluorescence-based cell sorting technologies becomes possible. Fluorescence-based identification of labeled cells enables differentation between cells tracked to a certain location, since nanostructure administration, and those present beforehand. In animal models of stroke, modifying the timepoint of nanostructure administration would enable the differentiation between macrophages that migrated to the stroke site immediately following stroke onset, and macrophages that migrated following tissue reperfusion. This could be examined using confocal microscopy, to preserve spatial information, or by flow cytometric analysis for macroscopic evaluation.

It is anticipated that nanostructure degradation with dye release will occur following internalization and this property suggests that 
these nanomaterials could potentially serve as the basis for new subcellular imaging contrast agents or for targeted drug delivery.

\section{Acknowledgements}

We acknowledge the financial support of the Health Research Board of Ireland and Science Foundation Ireland.

\section{Notes and references}

1 P. Jendelova, V. Herynek, L. Urdzikova, K. Glogarova, S. Rahmatova, I. Fales, B. Andersson, P. Prochazka, J. Zamecnik, T. Eckschlager, P. Kobylka, M. Hajek and E. Sykova, Cell Transplant, 2005, 14, 173-182.

2 S. A. Anderson, J. Shukaliak-Quandt, E. K. Jordan, A. S. Arbab, R. Martin, H. McFarland and J. A. Frank, Ann. Neurol., 2004, 55, 654-659.

3 G. M. Lanza, X. Yu, P. M. Winter, D. R. Abendschein, K. K. Karukstis, M. J. Scott, L. K. Chinen, R. W. Fuhrhop, D. E. Scherrer and S. A. Wickline, Circulation, 2002, 106, 2842-2847.

4 J. Krejci, J. Pachernik, A. Hampl and P. Dvorak, Gen. Physiol. Biophys., 2008, 27, 164-173.

5 I. Hilger, R. Hergt and W. A. Kaiser, IEE Proc. Nanobiotechnol., 2005, 152, 33-39.

6 B. Brochet, M. S. Deloire, T. Touil, O. Anne, J. M. Caille, V. Dousset and K. G. Petry, Neuroimage, 2006, 32, 266-274.

7 R. Weber, S. Wegener, P. Ramos-Cabrer, D. Wiedermann and M. Hoehn, Magn. Reson. Med., 2005, 54, 59-66.

8 J. B. Pawley and B. R. Masters, Journal of Biomedical Optics, 2008, 13, 029902-029903.
9 S. Corr, Y. Rakovich and Y. Gun'ko, Nanoscale Research Letters, 2008, 3, 87-104

10 S. Laurent, D. Forge, M. Port, A. Roch, C. Robic, L. Vander Elst and R. N. Muller, Chem. Rev., 2008, 108, 2064-2110.

11 N. Nitin, L. E. LaConte, O. Zurkiya, X. Hu and G. Bao, J. Biol. Inorg. Chem., 2004, 9, 706-712.

12 Y. Sahoo, A. Goodarzi, M. T. Swihart, T. Y. Ohulchanskyy, N. Kaur, E. P. Furlani and P. N. Prasad, J. Phys. Chem. B, 2005, 109, 38793885.

13 F. Bertorelle, C. Wilhelm, J. Roger, F. Gazeau, C. Menager and V. Cabuil, Langmuir, 2006, 22, 5385-5391.

14 C. Becker, M. Hodenius, G. Blendinger, A. Sechi, T. Hieronymus, D. Müller-Schulte, T. Schmitz-Rode and M. Zenke, Journal of Magnetism and Magnetic Materials, 2007, 311, 234-237.

15 O. Rodriguez, S. Fricke, C. Chien, L. Dettin, J. VanMeter, E. Shapiro, H. N. Dai, M. Casimiro, L. Ileva, J. Dagata, M. D. Johnson, M. P. Lisanti, A. Koretsky and C. Albanese, Cell Cycle, 2006, 5, 113-119.

16 R. Weissleder, K. Kelly, E. Y. Sun, T. Shtatland and L. Josephson, Nat. Biotechnol., 2005, 23, 1418-1423.

17 S. A. Corr, A. O’Byrne, Y. K. Gun'ko, S. Ghosh, D. F. Brougham, S. Mitchell, Y. Volkov and A. Prina-Mello, Chem. Commun., 2006, $4474-4476$.

18 S. A. Corr, S. J. Byrne, R. Tekoriute, C. J. Meledandri, D. F. Brougham, M. Lynch, C. Kerskens, L. O'Dwyer and Y. K. Gun'ko, J. Am. Chem. Soc., 2008, 130, 4214- 4215.

19 S. A. Corr, Y. K. Gun'ko, R. Tekoriute, C. J. Meledandri and D. F. Brougham, The Journal of Physical Chemistry C, 2008, 112, 13324-13327.

20 X. Hong, J. Li, M. Wang, J. Xu, W. Guo, J. Li, Y. Bai and T. Li, Chemistry of Materials, 2004, 16, 4022-4027.

21 M. Rausch, P. Hiestand, D. Baumann, C. Cannet and M. Rudin, Magn. Reson. Med., 2003, 50, 309-314. 